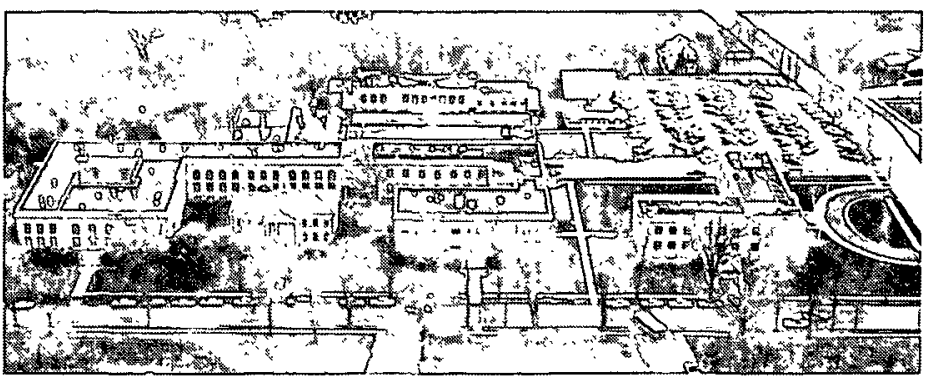

THE INSTITUTE OF PAPER CHEMISTRY, APPLETON, WISCONSIN

IPC TECHNICAL PAPER SERIES

NUMBER 320

AN ULTRASONIC TECHNIQUE FOR TESTING THE ORTHOTROPIC SYMMETRY OF POLYMERIC SHEETS BY MEASURING THEIR ELASTIC SHEAR COUPLING COEFFICIENTS

C. C. HABEGER 


\title{
An Ultrasonic Technique for Testing the Orthotropic Symmetry of \\ Polymeric Sheets by Measuring Their Elastic Shear \\ Coupling Coefficients
}

\author{
C. C. Habeger
}

\begin{abstract}
This manuscript is based on results obtained in IPC research and has been submitted for consideration for publication in the Transactions of ASME: Journal of Engineering Materials and Technology
\end{abstract}

Copyright, 1989, by The Institute of Paper Chemistry

For Members Only

NOTICE \& DISCLAIMER

The Institute of Paper Chemistry (IPC) has provided a high standard of professional service and has exerted its best efforts within the time and funds available for this project. The information and conclusions are advisory and are intended only for the internal use by any company who may receive this report. Each company must decide for itself the best approach to solving any problems it may have and how, or whether, this reported information should be considered in its approach.

IPC does not recommend particular products, procedures, matterials, or services. These are included only in the interest of completeness within a laboratory context and budgetarv constraint. Actual products, procedures, materials, and services used may differ and are peculiar to the operations of each company.

In no event shall IPC or its employees and agents have any obligation or liability for damages, including, but not limited to. consequential damages, arising out of or in connection w ith any company's use of, or inability to use, the reported iniormation. IPC provides no warranty or guaranty of results. 
An Ultrasonic Technique for Testing the Orthotropic Symmetry of Polymeric Sheets by Measuring their Elastic Shear Coupling Coefficients

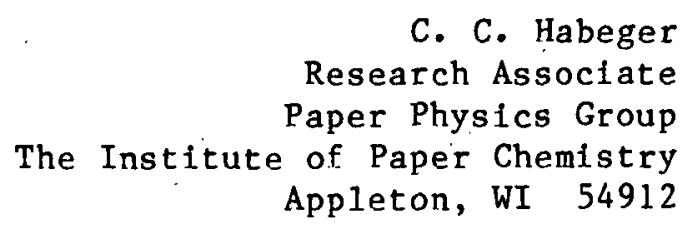

\section{Abstract}

An ultrasonic method which allows one to determine the in-plane elastic stiffnesses of thin polymeric sheets is described. The determination is complete, as it includes the shear coupling coefficients. Sheets are often assumed to display orthotropic symmetry, which means that the shear coupling coefficients are zero along the principal axes. The shear coupling coefficients can now be independently calculated, and there is a test of the validity of the orthotropic assumption. A quantity called the nonorthotropic angle is presented as a coordinate-independent measure of the lack of orthotropic response. Results from a polyester sheet demonstrate that significant nonorthotropic behavior is encountered in commercial plastic sheets. Stiffnesses calculated from tests conducted on laminated sheets are shown to be in good agreement with stiffnesses predicted from measurements on individual plies. The technique is argued to be self-consistent and an attempt is made to convince the reader that this is a legitimate way to characterize all the in-plane elastic stiffnesses of thin sheets. 


\section{Introduction}

The physical properties of commercial polymeric sheets are often anisotropic. In the case of paper, the fibers are preferentially aligned in the direction of manufacture (the machine direction of $M D$ ), and $M D$ tension is applied to the web during drying. These factors cause the final product to be stronger and more rigid in the MD than in the direction perpendicular to manufacture (the cross direction or $C D)$. Plastic films, extruded under MD tension, are also stiffer and stronger in the MD.

To simplify mathematical analyses of polymeric sheets, it is generally assumed that they exhibit orthotropic symmetry. This means that there are two perpendicular planes of reflectional symmetry. It is usually argued from the symmetries of manufacture that the reflectional symmetry planes are the plane determined by the MD and the thickness direction and the plane determined by the $\mathrm{CD}$ and the thickness direction. Sometimes, due to misalignment of a head box in paper manufacture or to off-axis tension in plastic fllm extrusion, the direction of greatest strength and stiffness is not along the MD. Nonetheless, it is. still assumed that the principal axes of stiffness (wherever they may be) determine planes of orthotropic symmetry.

Under the orthotropic assumption, the elastic shear coupling coefficients are zero, when measured along a principal axis. This means that normal stresses along a principal axis do not produce shear strains and vice versa. The technique described below allows one to calculate the shear coupling coefficients and to test the orthotropic assumption. Results will be discussed for a polyester sheet and a polypropylene sheet. It will be argued that within the sensitivity of the measurement the polypropylene sheet is orthotropic. The 
polyester sheet, however, will be shown to have shear coupling coefficients significantly different from zero along its princlpal axes, and it will thereby be deemed nonorthotropic. For the sake of increasing the confidence of the author and the reader, it will also be demonstrated, by testing polyester laminates, that the determinations are self-consistent.

\section{Background}

In the body of this paper, the time-of-flight velocity of in-plane ultrasonic waves in thin sheets will be discussed. A sheet can be considered thin if its thickness is much smaller than the acoustic wavelength. At the frequency of operation (about $80 \mathrm{kHz}$ ) wavelengths in polymers are over a centimeter, and this is a valid hypothesis for thin sheets. When the surfaces of a thin sheet are unconstrained (as will be the case), it is appropriate to assume that the sheet is in a state of plane stress and that there is no thickness direction variability in strain. For plane stress deformations the in-plane engineering strains, $\varepsilon_{i}(i=1,2,6)$, are related to the in-plane stresses, $\sigma_{i}$, through the planar elastic stiffnesses, $Q_{i j}$, as in Eq. (1).1

$$
\begin{aligned}
& \sigma_{1}=Q_{11} \varepsilon_{1}+Q_{12} \varepsilon_{2}+Q_{16} \varepsilon_{6} \\
& \sigma_{2}=Q_{12} \varepsilon_{1}+Q_{22} \varepsilon_{2}+Q_{26} \varepsilon_{6} \\
& \sigma_{6}=Q_{16} \varepsilon_{1}+Q_{26} \varepsilon_{2}+Q_{66} \varepsilon_{6} .
\end{aligned}
$$

The reader should be aware that $Q_{i j}$ 's differ slightly from the in-plane portion of the bulk stiffnesses, $C_{i j}$ 's, which relate in-plane stresses and strains when there is zero out-of-plane strain (rather than zero out-of-plane stress). In the description of acoustic wave propagation, it is convenient to introduce the mass specific planar stiffnesses, $q_{i j}$, where $q_{i j}=Q_{i j} /$ density $(i, j=1,2,6)$. The shear coupling coefficients, $Q_{16}$ and $Q_{26}$, in $\mathrm{Eq}$. (1) are zero for orthotropic 
sheets when the 1 and 2 axes determine the planes of orthotropic symmetry. They are not in general zero of f-axis in orthotropic sheets [Tsai and Hahn (1980)], or along any axis in nonorthotropic sheets.

It is straightforward to demonstrate [as Musgrave (1954) does in the analogous case of bulk stiffnesses] that the phase velocities, $V_{p}$, for plane harmonic waves in thin anisotropic plates are

$$
v_{p}^{2}=1 / 2\left[A \pm\left(A^{2}-4 B\right)^{1 / 2}\right]
$$

where $A$ and $B$ are defined in terms of the $q_{i j}$ 's and the angle, $\theta$, of propagation of the plane wave with respect to the 1 axis as in Eq. (3) and (4).

$$
\begin{gathered}
A=\cos ^{2} \theta q_{11}+\sin ^{2} \theta q_{22}+q_{66}+2 \cos \theta \sin \theta\left(q_{16}+q_{26}\right) \\
B=\left(\cos ^{2} \theta q_{11}+\sin ^{2} \theta q_{66}+2 \cos \theta \sin \theta q_{16}\right)\left(\sin ^{2} \theta q_{22}+\cos ^{2} \theta q_{66}+\right. \\
\left.2 \cos \theta \sin q_{26}\right)-\left[\cos ^{2} \theta q_{16}+\sin ^{2} \theta q_{26}+\cos \theta \sin \theta\left(q_{12}+q_{66}\right)\right]^{2} .
\end{gathered}
$$

The plus sign in Eq. (2) pertains to the phase velocity of the quasi-longitudinal mode, while the minus sign corresponds to the velocity of the slower traveling quasi-transverse mode [Musgrave (1954)].

From Eq. (2)-(4) it is clear that the phase velocity as a function of angle of propagation depends on all five independent planar stiffnesses. The planar stiffnesses could be determined by measuring the phase velocity of plane waves in many directions and adjusting the values of the $q_{i j}$ 's to get a best fit of Eq. (2) to the experimental results. However, plane wave propagation can be experimentally approximated only if the lateral extent of the transducers is much greater than the transducer separation. Transducers of these dimensions are not practical for testing polymeric sheets. In fact, the better approach is to 
employ transducers which can be modeled as point sources, since their contact dimensions are much less than the transducer separation. Musgrave (1954) has demonstrated that in anisotropic materials the phase velocities measured between point transducers is different from the phase velocity of plane waves as described by Eq. (2).

Musgrave calls the phase velocity, $\nabla_{i}$, between point sources the velocity of information propagation, and he shows that there is a one to one graphical relationship between polar plots of $v_{i}$ as a function of $\theta$ and polar plots of $v_{p}$ as a function of $\theta$. This is: a line drawn through a point on the plane wave polar plot perpendicular to the radial direction will be tangent to the information propagation polar plot. Using Musgrave's graphical construction, it is. feasible to first experimentally generate the information propagation polar plot, to construct the plane wave polar plot, and to then find the $q_{i j}$ 's that produce a best fit to the plane wave polar plot. This is the basic approach adopted in the analysis described below.

\section{Experiment}

The velocity measurements were performed with a robotic, in-plane, ultrasonic tester developed at The Institute of Paper Chemistry [Van Zummeren, Young, Habeger, Baum, and Treleven (1987); Habeger, Van Zummeren, Wink, Pankonin, and Goodlin (1989)]. This is comprised of a commercial laboratory robot (Mitsubishi RM 501), a specially designed end effector, and some external electronic instrumentation. The end effector mounts to the end of the robot arm and houses two specially-designed, miniature, bimorph transducers [Habeger, Van Zummeren, Wink, Pankonin, and Goodlin (1989)]. There are double-action air cylinders, as part of the end effector, which can rotate each transducer $90^{\circ}$ about its axis. 
This allows for the detection of both longitudinal and transverse waves with the same transducers. A third double-action air cylinder, also on the end effector, drives a carriage to which one transducer is mounted. By activating this cylinder, one of two different transducer separations ( 3 or $8 \mathrm{~cm}$ ) can be selected. The robot arm is capable of dead-weight loading the transducers to a horizontal sample over a 4 by 5 inch span, with the displacement between transducers oriented at any in-plane angle. Al.l mechanical motions of the robot and end effector are controlled by PC class AT personal computer.

A typical velocity measurement sequence begins with the computer instructing the robot to lower the end effector to the sample with the transducers in the "near" separation. The computer triggers a function generator to excite one of the transducers with a 20 volt, single-cycle, $80 \mathrm{kHz}$ sine wave. This generates an ultrasonic wave in the sample which is detected by the other transducer. The received signal is amplified and applied to a digital oscilloscope, where it is digitized at a $10 \mathrm{MHz}$ rate and communicated over a G.P.I.B. bus to the computer. This is repeated a preset number of times and the computer digitally averages the multiple received signals. The end effector is then lifted from the sample; the cylinder is fired to separate the transducers; and the transducers are returned to the sample. A composite "far" signal is generated in the same manner. The computer calculates the cross-correlation function for the two signals, and from the maximum in this function it determines the time-of-flight difference between the two signals [Bloch (1977)]. To avoid interference from edge reflections, only the first half cycle of the near signal is used in the calculation. The time-of-flight velocity is then calculated as the separation difference divided by the time difference. The robot raises the transducers and repeats the velocity determination at another location 
on the sample. For more details on the operation and construction of the instrument the reader is referred to the earlier publications IVan Zummeren, Young, Habeger, Baum, and Treleven (1987); Habeger, Van Zummeren, Wink, Pankonin, and Good1in (1989)].

The test procedure for the experiments reported in the paper is a three step process. Longitudinal velocity measurements are first made at $5^{\circ}$ increments of the transducer orientation angle. At each orientation, tests are conducted at eight locations on the sample. About 45 minutes are required to perform the necessary 288 velocity measurements. After the longitudinal testing is complete, sixteen transverse velocity measurements are made along the minor principal axis of moment of inertia of the plane wave velocity squared polar plot. The computer prints the values of the information propagation velocities squared and constructs a polar plot. The results for a polypropylene sample are presented in Fig. 1.

Fig. 1 here

The next task is to use the Musgrave construction to create a plane wave polar plot. As demonstrated for the polypropylene sheet in Fig. 2, the computer does the required calculations, prints the values of the plane wave velocities squared at $5^{\circ}$ increments, and produces a polar plot. Notice that along the principal axes the two figures display the same velocities, while the offaxis plane wave velocities are noticeably larger. These differences are exaggerated for sheets of higher anisotropy.

Fig. 2 here

Optimizing the stiffnesses to reproduce the plane wave polar plot is the last step. The specific shear stiffness, 966 , is set equal to the average of 
the sixteen transverse velocities determined in the first step. To start with, the sample is assumed to be orthotropic. This means $q_{16}$ and $q_{26}$ are zero, when referred to the axes of reflectional symmetry. The axes for calculation of the elastic coefficients are taken as the principal axes of moment of inertia of the plane wave velocity squared polar plot. If the material is orthotropic, these are the reflectional symmetry axes. The computer now optimizes in a coordinate system aligned to the principal axes the three unknown parameters $\left(q_{11}, q_{22}\right.$, and $q_{12}$ ) to produce a minimum value in the sum of the absolute relative differences between experiment and theory in the plane wave velocity squared polar plot. These results, along with the minimum average relative error, are reported as shown in Fig. 3. The optimization is then repeated. This time nonzero values of $q_{16}$ and $q_{26}$ are allowed. The new stiffnesses and error values are printed. By rotating the general stiffnesses tensor, the values of $q_{11}$ are calculated as a function of $\theta$, and a third polar plot is generated. Notice that for this sample the shear coupling terms are very small, and little improvement in the relative error is achieved by, their addition. The minimum average relative error has been found to almost always be under 0.005 for a wide variety of papers and plastic sheets. This demonstrates that the theoretical framework fits the experimental data and is taken as evidence for the validity of the general approach.

Fig. 3 here

A parameter, called the nonorthotropic angle, is now presented as a quantitative indicator of the lack of orthotropic behavior. It is easily shown [Tsai and Hahn (1980)] that the derivatives of the stiffnesses with respect to orientation are as follows: $\mathrm{dq}_{11} / \mathrm{d} \theta=-4 \mathrm{q}_{16}, \mathrm{dq}_{22} / \mathrm{d} \theta=4 \mathrm{q}_{26}, \mathrm{dq}_{16} / \mathrm{d} \theta=\mathrm{q}_{11}-2 \mathrm{q}_{66}-\mathrm{q}_{12}$, and $\mathrm{dq}_{26} / \mathrm{d} \theta=-\mathrm{q}_{22}+2 \mathrm{q}_{66}+\mathrm{q}_{12}$. Notice that $\mathrm{q}_{16}$ is zero when $\mathrm{q}_{11}$ is an extremum 
and that $q_{26}$ is zero when $q_{22}$ is an extremum. If a material is orthotropic, $q_{16}$ and $q_{26}$ are zero and $q_{11}$ and $q_{22}$ are extrema along the principal axes. If a material is not orthotropic, $q_{16}$ and $q_{26}$ are not zero at the same angle, the extrema of $q_{11}$ and $q_{22}$ do not coincide, and the extrema of $q_{11}$ and $q_{22}$ are not separated by $90^{\circ}$. The nonorthotropic angle, $\Phi$, is defined as the angular $\ldots$ separation between the nul1 values of $q_{26}$ and $q_{16}$. This, of course, also equals the angle between an extremum in $q_{22}$ and an extremum in $q_{11}$. When $\Phi$ is small (ignoring derivatives of second order and higher in $q_{16}$ and $q_{26}$ ), the nonorthotropic angle is

$$
\Phi \approx-q_{16} /\left(q_{11}-q_{12}-2 q_{66}\right)-q_{26} /\left(q_{22}-q_{12}-2 q_{66}\right) .
$$

The nonorthotropic angle is a coordinate independent parameter which is directly related to the prominent behavioral peculiarities of nonorthotropic sheets. Therefore, it will be used as the principle measure of nonorthotropic response, and relatively large values of $\Phi$ [printed out according to Eq. (5) as in Fig. 3] are taken to mean that the orthotropic assumption is inappropriate for the sample in question.

\section{Single Sheet Results}

Pertinent values (with one standard deviation uncertainties) for a $75 \mu \mathrm{m}$ thick polypropylene sheet and a $135 \mu \mathrm{m}$ thick polyester sheet are listed in Table 1. The values of $\mathrm{q}_{16}$ and $\mathrm{q}_{26}$ are measured relative to the principal axes of the moment of inertia of the plane wave velocity squared polar plot. The symbol $\mathrm{E}_{\mathrm{o}}$ represents the average relative error using the orthotropic assumption, and $E_{N}$ is the error when $q_{16}$ and $q_{26}$ are allowed to vary. 
Each number reported in Table 1 is the average of eight different runs (the product of 2304 velocity measurements). The region of the sheet sampled at each angle is slightly different, and, on a single run, variations over the sample can lead to artifacts in the polar plots. This complication was addressed by rotating the sample $90^{\circ}$ between runs and doing $50 \%$ of the runs on each side of the sample. In theory, turning a sheet over inverts $q_{16}$ and $q_{26}$. This phenomenon was observed experimentally, and it is presented as evidence for selfconsistency of the experiments. The results in Table' 1 are taken relative to one side of the sample which was arbitrarily designated as the top.

The two plastic sheets are representative of orthotropic and nonorthotropic behavior. For the polypropylene sheet, the shear coupling coefficients and the nonorthotropic angle are extremely small and not significantly different from zero at a reasonable confidence level. Also, the fit of theory to experiment is little improved by adjusting $q_{16}$ and $q_{26}$. The converse of all these observations are true for the polyester. The polyester sample is also interesting in that the axis of maximum stiffness deviates over $30^{\circ}$ from the MD. The third page report for one of the polyester runs is included as Fig. 4. Notice that the nonorthotropic behavior is manifest in a slight asymmetry of the polar plot relative to the principal axes.

Fig. 4 here

\section{Laminate Results}

The reported shear coupling coefficients (even those of the polyester) are admittedly small, and it is legitimate to question their significance. Further demonstrations that they are not artifacts of the experiment are necessary before they can be taken seriously. An ideal approach would be to test sheets 
with independently determined shear coupling coefficients. However, to the author's knowledge, there is no comparable method for measuring shear coupling coefficients in sheets.

Measurements on laminates was the method adopted here, to inspect the foundations of the technique. The laminates were made by bonding together plastic sheets whose general elastic constants had been measured. The effective stiffnesses of the laminates was calculated from the stiffnesses of their layers and compared to the values measured on the laminates. This approach can work only if the layers are we11-bonded, with a very thin layer of adhesive. After considerable-trial and error, a method was found which was successful with the polyester sheets, only. Polyester sheets were placed in contact, with a small amount of Locktite 447 "surface insensitive Instant adhesive" applied inside, , along one edge. This edge and the two adjacent edges were taped to keep the $\therefore$ adhesive from escaping. The laminate was then turned through the nip of a heavily-loaded, rubber-rolled wringer. Then the laminate was sandwiched between flat metal plates, and the adhesive was allowed to cure for one day: The suitability of the lamination process was verified by making two ply laminates of polyester sheets. If the bonding was satisfactory, the $q_{i j}$ 's of the laminate would equal those of the plies. Within one standard deviation, this was the case for all of the stiffnesses (including $q_{16}$ and ' $q_{26}$ ).

The theoretical relationships between the elastic properties of the laminate and those of the plies are simple. Since the wavelength is large compared to the laminate thickness, the assumption of plane stress remains valid. Therefore, the effective elastic properties of the laminate are the average of. the plies [Tsai and Hahn (1980)], and, as all plies have the same density, the 
$q_{1 j}$ 's are merely the average of the layers. To predict the laminate stiffnesses, the ply stiffnesses are rotated to the axis of interest and averaged.

Four different laminates were fabricated from polyester sheets, taken from the same roll as that in Table 1 and tested. Two were "flip" laminates, and two were "rotation" laminates. An "off-axis flip laminate" was made by rotating one sheet $180^{\circ}$ about the $M D$ axis and bonding it to a similar sheet. The major principal axes were about $33^{\circ}$ from the MD, making the principal axis of the plies about $66^{\circ}$ apart. An "on-axis flip laminate" was also constructed. This time. one sheet was rotated about a principal axis, and the principal axes of the plies were aligned. The plies of each laminate were chosen to have almost.equal stiffnesses. Since flipping a sheet inverts its shear coupling coefficients and since the laminate stiffnesses are the average of the plies, the laminates. approximate orthotropic behavior better than the plies. The on-axis flip laminate has roughly the same MD to $C D$ stiffness ratio as the plies, while the offaxis laminate is a squarer sheet. The results for the flip laminates are presented in Table 2 .

Table 2 here

In Table 2, the symbol, $\alpha$, represents the angle between the rotation axis and the major principal axis of moment of inertia of the plane wave velocity squared polar plot. The $\alpha$ for the laminate is that determined by the measurements on the laminate, and the experimental stiffnesses are relative to that axis.

The agreement between experimental flip laminate stiffnesses and those calculated from the ply stiffnesses is impressive. Note particularly that, as predicted, very small shear coupling coeficients and $\Phi$ values were measured for the laminate. 
A "two-ply rotation laminate" and a "three-ply rotation laminate" were also fabricated. The major principal axes of the layers in the two-ply sheet are at $90^{\circ}$. This produces a sheet with a decreased nonorthotropic angle and nearly cubic symmetry. The principal axes of the middle ply of the three-ply laminate is rotated $90^{\circ}$ from those on the outside. This sheet should be squarer than a single ply, and it should have an even larger nonorthotropic angle. The results are in Table 3.

Table 3 here

The two-ply laminate in Table 3 is a very square sheet, and the determination of the principal axes is unstable. Therefore, there was much variability in the orientation of these axes as determined by the computer program. To get the results on a common basis, the stiffnesses from each run were rotated to the theoretical princlpal axis and averaged at that angle. The value of the principal axis listed in Table 3 is in parentheses to indicate that it was not found experimentally. Excellent agreement between the experimental and theoretical stiffnesses, with the possible exception of the shear coupling coefficients, was realized for the two-ply rotation laminate. Since the shear coupling coefficients are changing rapidly (in opposite directions) with angle near a principal axis, the difference between experiment and theory can be attributed to small errors in the orientation of the principal axes. The nonorthotropic angle is a coordinate-independent parameter, which is not influenced by the cholse of principal axes. It therefore provides another (perhaps fairer) way to compare shear coupling results. Both values of $\Phi$ are extremely small. Thus theory and experiment agree that the two-ply rotation produces a nearly cubic sheet. 
For the three-ply laminate, the values of $f^{\prime} q 66$, the shear stiffness, do not compare as we1l as for the others. This may findicate that the lamination process is not as effective with three layers. Since the determination of $\mathrm{q}_{12}$ is very sensitive to 966 , the low shear stiffness as measured in the laminate. results in a large disparity in $q_{12}$ values. The three-ply laminate was the only highly nonorthotropic sheet produced, and although the shear values are in question, its results are included to show that theory and experiment are in concurrence on the lack of orthotropic symmetry. In this case, the values of $\Phi$ were too large to be calculated using Eq. (5), and instead they were obtained from complete plots of the shear coupling coefficients. Notice that both values of $\Phi$ are almost $20^{\circ}$. This means that the maximum in $q_{11}$ and the minimum in $q_{22}$ are nearly $20^{\circ}$ apart. The effect of this was manifested in the raw experimental data which shows approximately a $70^{\circ}$ spacing between a maximum and a minimum in the longitudinal velocity, see Fig. 5 .

Fig. 5 here

\section{Conclusions}

It has been demonstrated that by using an automated ultrasonic apparatus it is possible to perform the large number of measurements necessary to make repeatable determinations of all the in-plane elastic stiffnesses (including the shear coupling coefficients) of a polymeric sheet. The results are shown to be consistent in that they yield the expected output when laminates are tested. To the author's knowledge, this is the first instrument developed to routinely measure the shear coupling coefficients on sheets.

Sheets without orthotropic symmetry can develop shear strain when normal stresses are applied along any axis. This can translate into out-of-plane 
buckling and wrinkling and can cause numerous difficulties in handling and end-use performance. Measurements of shear coupling coefficients are clearly important for characterizing the response of thin sheets. The limited survey of plastic sheets done in conjunction with this study revealed that at least one commercially available polyester sheet displays shear coupling behaviors that are not consistent with orthotropic symmetry.

\section{References}

Bloch, S., Am. J. Phys., 45, 538 (1977).

Habeger, C., Van Zummeren, M., Wink, W., Pankonin, B., and Goodlin, R., Tappi, to be published, 1989.

Musgrave, M., Proc. Royal Soc., A226 (1166), 339 (1954).

Tsai, S. and Hahn, H., Introduction to Composite Materials, Technomic, Lancaster, PA, 1980.

Van Zummeren, M., Young, D., Habeger, C., Baum, G., and Treleven, R., Ultrasonics, 25, 288 (1987). 
Figure Captions

Fig. 1. A computer printout of the measured values of the information propagation velocity squared for a polypropylene sheet as a function of clockwise angle from the MD.

Fig. 2. A computer printout of the plane wave velocity squared values using Musgrave's construction and the results from Figure 1.

Fig. 3. A computer printout of the elastic stiffnesses determined from a best fit to the Figure 2 polar plot.

Fig. 4. A computer printout of the elastic stiffnesses of a polyester sheet from $a$ best fit to the plane waves velocity squared polar plot.

Fig. 5. A computer printout of the measured values of the information propagation velocity squared for the three-ply polyester laminate. 
Table 1. Elastic parameters for single plastic sheets

$$
\text { Quantity }
$$

$q_{16}\left(\mathrm{~km}^{2} / \mathrm{s}^{2}\right)$
$q_{26}\left(\mathrm{~km}^{2} / \mathrm{s}^{2}\right)$
$\Phi$
$E_{O}$
$E_{N}$

Polypropylene

$0.000 \pm 0.005$

$0.002 \pm 0.004$

$0.01^{\circ} \pm 0.04$

0.00413

0.0058
Polyester

$-0.036 \pm 0.007$

$0.047 \pm 0.012$

$4.8^{\circ} \pm 1.1$

0.00406

0.0027 
Table 2. Elastic parameters for plastic flip laminates

\author{
OFF-AXIS FLIP LAMINATE
}

$\begin{array}{lccc}\text { Top } & \text { Bottom } & \text { Laminate } & \text { Laminate } \\ \text { Ply } & \text { P1y } & \text { Theory } & \text { Experiment }\end{array}$

$\begin{array}{llllll}\mathrm{q}_{11}\left(\mathrm{~km}^{2} / \mathrm{s}^{2}\right) & 6.51 & 6.55 & 5.80 & 5.78 \pm 0.02 \\ \mathrm{q}_{22}\left(\mathrm{~km}^{2} / \mathrm{s}^{2}\right) & 4.36 & 4.34 & 4.92 & 4.91 \pm 0.02 \\ \mathrm{q}_{66}\left(\mathrm{~km}^{2} / \mathrm{s}^{2}\right) & 1.75 & 1.75 & 1.85 & 1.84 \pm 0.01 \\ \mathrm{q}_{12}\left(\mathrm{~km}^{2} / \mathrm{s}^{2}\right) & 1.63 & 1.65 & 1.73 & 1.72 \pm 0.02 \\ \mathrm{q}_{16}\left(\mathrm{~km}^{2} / \mathrm{s}^{2}\right) & -0.035 & 0.038 & 0.002 & 0.002 \pm 0.007 \\ \mathrm{q}_{26}\left(\mathrm{~km}^{2} / \mathrm{s}^{2}\right) & 0.040 & -0.050 & -0.002 & -0.002 \pm 0.007 \\ \alpha & 33.1^{\circ} & -33.5^{\circ} & -0.7^{\circ} & -2.0^{\circ} \pm 1.0 \\ \Phi & & 4.2^{\circ} & -5.0^{\circ} & -0.5^{\circ} & -1.3^{\circ} \pm 1.8\end{array}$

\title{
ON-AXIS FLIP LAMINATE
}

$\begin{array}{llllll}\mathrm{q}_{11}\left(\mathrm{~km}^{2} / \mathrm{s}^{2}\right) & 6.50 & 6.56 & 6.53 & 6.48 \pm 0.04 \\ \mathrm{q}_{22}\left(\mathrm{~km}^{2} / \mathrm{s}^{2}\right) & 4.38 & 4.36 & 4.38 & 4.34 & \pm 0.02 \\ \mathrm{q}_{66}\left(\mathrm{~km}^{2} / \mathrm{s}^{2}\right) & 1.75 & 1.75 & 1.75 & 1.76 \pm 0.01 \\ \mathrm{q}_{12}\left(\mathrm{~km}^{2} / \mathrm{s}^{2}\right) & 1.65 & 1.65 & 1.64 & 1.62 \pm 0.03 \\ \mathrm{q}_{16}\left(\mathrm{~km}^{2} / \mathrm{s}^{2}\right) & -0.043 & 0.045 & 0.001 & 0.002 \pm 0.004 \\ \mathrm{q}_{26}\left(\mathrm{~km}^{2} / \mathrm{s}^{2}\right) & 0.055 & -0.058 & -0.001 & -0.004 \pm 0.005 \\ \alpha & -0.9^{\circ} & 0.6^{\circ} & -0.2^{\circ} & -0.1^{\circ} \pm 0.6 \\ \Phi & & 6.0^{\circ} & -6.1^{\circ} & -0.0^{\circ} & -0.4^{\circ} \pm 0.5\end{array}$


Table 3. Elastic parameters for rotation laminates

TWO-PLY ROTATION LAMINATE

$\begin{array}{lccc}\text { Top } & \text { Bottom } & \text { Laminate } & \text { Laminate } \\ \text { P1y } & \text { P1y } & \text { Theory } & \text { Experiment }\end{array}$

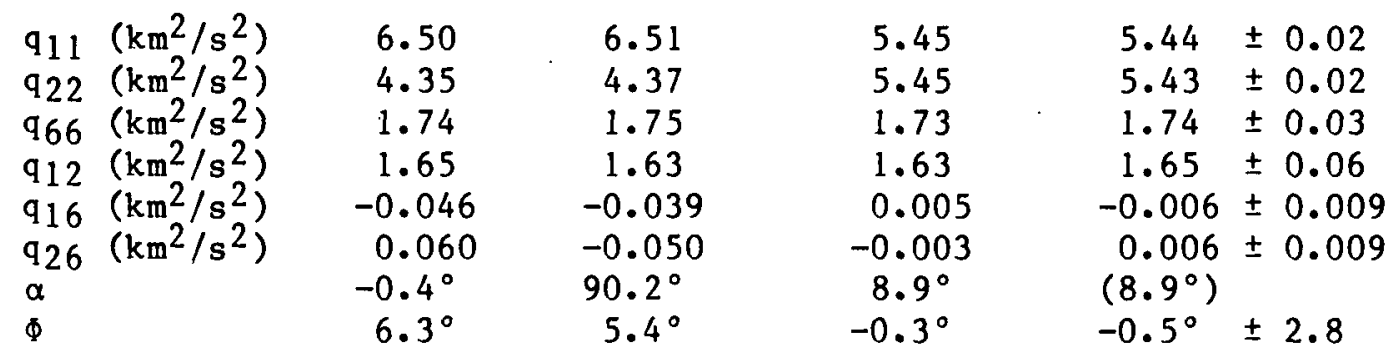

THREE-PLY ROTATION LAMINATE

$\begin{array}{lcccrc}\mathrm{q}_{11}\left(\mathrm{~km}^{2} / \mathrm{s}^{2}\right) & 6.53 & 6.47 & 5.80 & 5.79 \pm 0.04 \\ \mathrm{q}_{22}\left(\mathrm{~km}^{2} / \mathrm{s}^{2}\right) & 4.34 & 4.34 & 5.05 & 5.04 \pm 0.03 \\ \mathrm{q}_{66}\left(\mathrm{~km}^{2} / \mathrm{s}^{2}\right) & 1.75 & 1.76 & 1.75 & 1.73 \pm 0.04 \\ \mathrm{q}_{12}\left(\mathrm{~km}^{2} / \mathrm{s}^{2}\right) & 1.61 & 1.61 & 1.61 & 1.71 \pm 0.04 \\ \mathrm{q}_{16}\left(\mathrm{~km}^{2} / \mathrm{s}^{2}\right) & -0.040 & -0.045 & -0.046 & -0.061 \pm 0.011 \\ \mathrm{q}_{26}\left(\mathrm{~km}^{2} / \mathrm{s}^{2}\right) & 0.051 & 0.059 & 0.049 & 0.065 \pm 0.011 \\ \alpha & 33.3^{\circ} & -33.8^{\circ} & 33.3^{\circ} & 33.5^{\circ} \pm 1.1 \\ \Phi & & 5.4^{\circ} & 6.2^{\circ} & 18.4^{\circ} & 19.3^{\circ}\end{array}$


THE IHSTITUTE OF PAPER CHEMISTRY

ROBOTIC IN-PLAKE ULTRASONIC VELOCITIES

POLAR PLOT OF LONGITUDIMAL INFORMATION PROPAGATION VELOCITY SOUARED

OPERATOR: C. C. Habeger

PROJECT : 3467
SAHPLE : Polypropylene AA top corner $273^{\circ} \mathrm{F}$

DATE: DECEMBER 6, 1988

SIGYALS AYERAGED PER MEASUREMEUT $=$

\begin{tabular}{|c|c|c|c|c|c|}
\hline $\begin{array}{c}\text { AKGLE } \\
\text { DEGREES }\end{array}$ & $\begin{array}{l}\text { VEL SOR } \\
\text { KH2/SEC2 }\end{array}$ & $\begin{array}{l}\text { COEF OF } \\
\text { VARIATIOA }\end{array}$ & $\begin{array}{c}\text { AMGLE } \\
\text { DEGREES }\end{array}$ & $\begin{array}{l}\text { VEL SOR } \\
\text { KH2/SEC2 }\end{array}$ & $\begin{array}{l}\text { COEF OF } \\
\text { VARIATION }\end{array}$ \\
\hline $\begin{array}{r}0 \\
5 \\
10 \\
15 \\
20 \\
25 \\
30 \\
35 \\
40 \\
45 \\
50 \\
55 \\
60 \\
65 \\
70 \\
75 \\
80 \\
85\end{array}$ & $\begin{array}{r}10.12 \\
10.00 \\
9.78 \\
9.32 \\
8.92 \\
8.33 \\
7.86 \\
7.38 \\
6.98 \\
6.62 \\
6.27 \\
6.02 \\
5.76 \\
5.55 \\
5.40 \\
5.29 \\
5.17 \\
5.11\end{array}$ & $\begin{array}{l}0.015 \\
0.008 \\
0.008 \\
0.010 \\
0.011 \\
0.011 \\
0.008 \\
0.004 \\
0.009 \\
0.004 \\
0.005 \\
0.006 \\
0.008 \\
0.008 \\
0.007 \\
0.004 \\
0.004 \\
0.007\end{array}$ & $\begin{array}{l}90 \\
95 \\
100 \\
105 \\
110 \\
115 \\
120 \\
125 \\
130 \\
135 \\
140 \\
145 \\
150 \\
155 \\
160 \\
165 \\
170 \\
175\end{array}$ & $\begin{array}{r}5.08 \\
5.12 \\
5.19 \\
5.29 \\
5.41 \\
5.59 \\
5.80 \\
6.04 \\
6.33 \\
6.63 \\
7.03 \\
7.46 \\
7.86 \\
8.37 \\
8.88 \\
9.37 \\
9.82 \\
10.02\end{array}$ & $\begin{array}{l}0.010 \\
0.007 \\
0.008 \\
0.009 \\
0.009 \\
0.008 \\
0.011 \\
0.006 \\
0.010 \\
0.007 \\
0.009 \\
0.007 \\
0.004 \\
0.006 \\
0.010 \\
0.005 \\
0.010 \\
0.009\end{array}$ \\
\hline
\end{tabular}

AREA $=166.7\left(k^{\wedge} 4 /\right.$ secc $\left.^{\wedge} 4\right)$

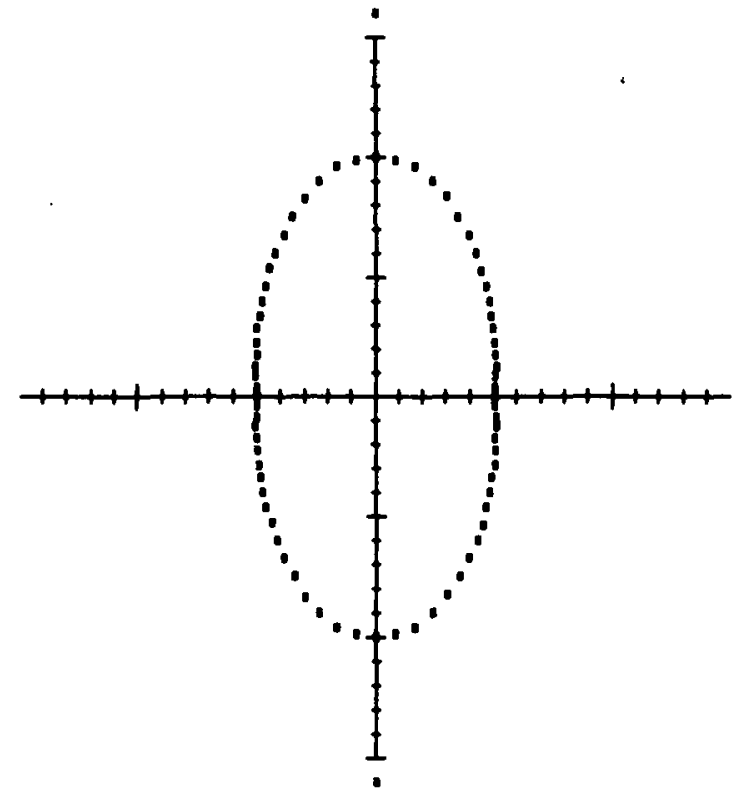

CD

MD

PLOT OP URL SQR US AMGLE

(Graph Scale $=1 \mathrm{~km} 2 / \sec ^{\wedge} 2 / d i v$ )

Fig. 1. A computer printout of the measured values of the information propagation velocity squared for a polypropylene sheet as a function of clockwise angle from the MD. 
THE INSTITUTE OF PAPER CHEMISTRY

ROBOTIC IN-PLAKE ULTRASONIC VELOCITIES

POLAR PLOT OF LOHGITUDIMAL IMFORMATIOA PROPAGATION VELOCITY SOUARED

\begin{tabular}{|c|c|c|c|c|c|c|}
\hline \multicolumn{7}{|c|}{$\begin{array}{lr}\text { OPERATOR: C. C. Habeger } & \text { DATE: DECEMBER 3, } 1988 \\
\text { PROJECT : } 3467 & \text { TIME: } 8: 45: 25 \\
\text { SAMPLE : Polyester trilaminate } 104-10690^{\circ}-105 & 72.5^{\circ}\end{array}$} \\
\hline \multicolumn{7}{|c|}{$\begin{array}{l}\text { SIGNALS AVERAGED PER MEASUREMENT } \\
\text { NUMBER OF TESTS PER ANGLE } \\
\text { SIGAAL DISTANCE } \\
\text { SAKPLE HOLDER NUKBER }\end{array}$} \\
\hline $\begin{array}{l}\text { ANGLE } \\
\text { DEGREES }\end{array}$ & $\begin{array}{l}\text { VEL SOR } \\
\text { KH2/SEC2 }\end{array}$ & $\begin{array}{l}\text { COEF OF } \\
\text { VARIATIOA }\end{array}$ & & $\begin{array}{l}\text { ANGLE } \\
\text { DEGREES }\end{array}$ & $\begin{array}{l}\text { VEL SQR } \\
\text { KH2/SEC2 }\end{array}$ & $\begin{array}{l}\text { COEF OF } \\
\text { VARIATIOK }\end{array}$ \\
\hline $\begin{array}{l}0 \\
5 \\
10 \\
15 \\
20 \\
25 \\
30 \\
35 \\
40 \\
45 \\
50 \\
55 \\
60 \\
65 \\
70 \\
75 \\
80 \\
85\end{array}$ & $\begin{array}{l}5.51 \\
5.36 \\
5.28 \\
5.21 \\
5.16 \\
5.11 \\
5.07 \\
5.05 \\
5.00 \\
5.03 \\
5.05 \\
5.12 \\
5.07 \\
5.10 \\
5.12 \\
5.15 \\
5.18 \\
5.22\end{array}$ & $\begin{array}{l}0.010 \\
0.015 \\
0.032 \\
0.023 \\
0.023 \\
0.021 \\
0.018 \\
0.020 \\
0.022 \\
0.015 \\
0.014 \\
0.016 \\
0.015 \\
0.012 \\
0.007 \\
0.007 \\
0.008 \\
0.011\end{array}$ & & $\begin{array}{l}90 \\
95 \\
100 \\
105 \\
110 \\
115 \\
120 \\
125 \\
130 \\
135 \\
140 \\
145 \\
150 \\
155 \\
160 \\
165 \\
170 \\
175\end{array}$ & $\begin{array}{l}5.28 \\
5.29 \\
5.28 \\
5.32 \\
5.39 \\
5.56 \\
5.50 \\
5.56 \\
5.65 \\
5.72 \\
5.74 \\
5.78 \\
5.86 \\
5.80 \\
5.80 \\
5.72 \\
5.66 \\
5.59\end{array}$ & $\begin{array}{l}0.010 \\
0.017 \\
0.017 \\
0.010 \\
0.016 \\
0.011 \\
0.021 \\
0.000 \\
0.013 \\
0.0118 \\
0.016 \\
0.014 \\
0.012 \\
0.015 \\
0.014 \\
0.028 \\
0.001 \\
0.013\end{array}$ \\
\hline
\end{tabular}

ANGLE TO PRIMCIPAL AXIS OF MOMENT OF INERTIA $=-34.8^{\circ}$ MD IS ALOHG RadiUS AREA $=90.7\left(\mathrm{~km}^{\wedge} 4 / \mathrm{BeC}^{\wedge} 4\right)$ MD-CD STIFFNESS RATID $=1.04$

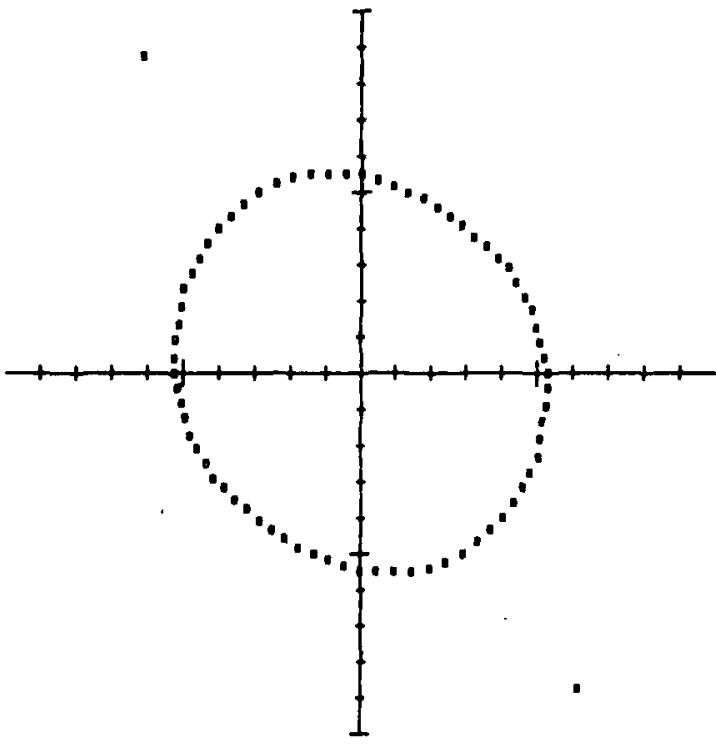

CD

MD

PLOT OF UBL SQR US ANGLE

(Graph Scale $=1 \mathrm{~km} 2 / \mathrm{sec}^{\wedge} 2 / \mathrm{div}$ )

Fig. 2. A computer printout of the plane wave velocity squared values using Musgrave's construction and the results from figure 1 . 
THE IMSTITUTE OF PAPER CHEMISTRY

ROBOTIC IN-PLANE ULTRASONIC VELOCITIES

POLAR PLOT OF LOKGITUdIMAL PHASE VELOCITY SOUARED -

OPERATOR: C. C. Habeger

SAHPLE : Polypropylene AA top corner $273^{\circ} \mathrm{F}$

DATE: DECEMEER 6, 1988

SIGNALS AVERAGED PER MEASUREMENT = NUHBER OF TESTS PER AHYLE $=8$

SIGKAL DISTANCE

SAMPLE HOLDER NUMBER

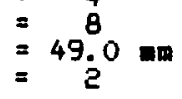

$\begin{array}{cccc}\begin{array}{c}\text { AHGLE } \\ \text { DEGREES }\end{array} & \begin{array}{c}\text { VEL SOR } \\ \text { KH2/SEC2 }\end{array} & \begin{array}{c}\text { AMGLE } \\ \text { DEGREES }\end{array} & \begin{array}{c}\text { YEL SOR } \\ \text { KH2/SEC2 }\end{array} \\ 0 & 10.12 & 90 & 5.08 \\ 5 & 10.04 & 95 & 5.15 \\ 10 & 9.92 & 100 & 5.25 \\ 15 & 9.71 & 105 & 5.42 \\ 20 & 9.49 & 110 & 5.64 \\ 25 & 9.13 & 115 & 5.91 \\ 30 & 8.70 & 120 & 6.21 \\ 35 & 9.32 & 125 & 6.59 \\ 40 & 7.88 & 130 & 6.96 \\ 45 & 7.35 & 135 & 7.39 \\ 50 & 6.94 & 140 & 7.85 \\ 55 & 6.52 & 145 & 8.79 \\ 60 & 6.18 & 150 & 8.75 \\ 65 & 5.85 & 155 & 9.16 \\ 70 & 5.61 & 160 & 9.52 \\ 75 & 5.39 & 165 & 9.74 \\ 80 & 5.25 & 170 & 9.94 \\ 85 & 5.13 & 175 & 10.04\end{array}$

AMGLE TO PRINCIPAL AXIS OF MOMENT OF INERTIA $=-0.2^{\circ}$ $A R E A=186.8\left(k^{\wedge} 4 / \sec ^{\wedge} 4\right)$

MD-CD STIFFNESS RATIO $=1.99$

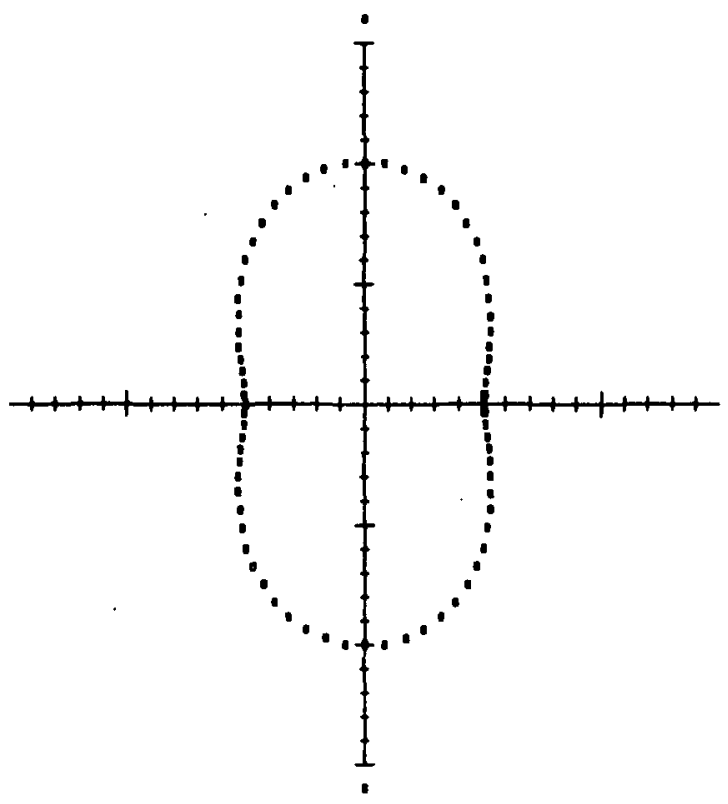

CD

HD

PLOT OF UEL SQR US ANGLE

(Graph Scale $\left.=1 \operatorname{lo} 2 / \sec ^{\wedge} 2 / d i v\right)$

Fig. 3. A computer printout of the elastic stiffnesses determined from a best fit to the Figure 2 polar plot. 
THE INSTITUTE OF PAPER CHEMISTRY

ROBOTIC IH-PLAKE ULTRASOHIC VELOCITIES

OPTIMUA MASS SPECIFIC STIFFUESSES FROK LEAST SOUARED

FIT. TO LONGITUDIMAL PHASE VELOCITY

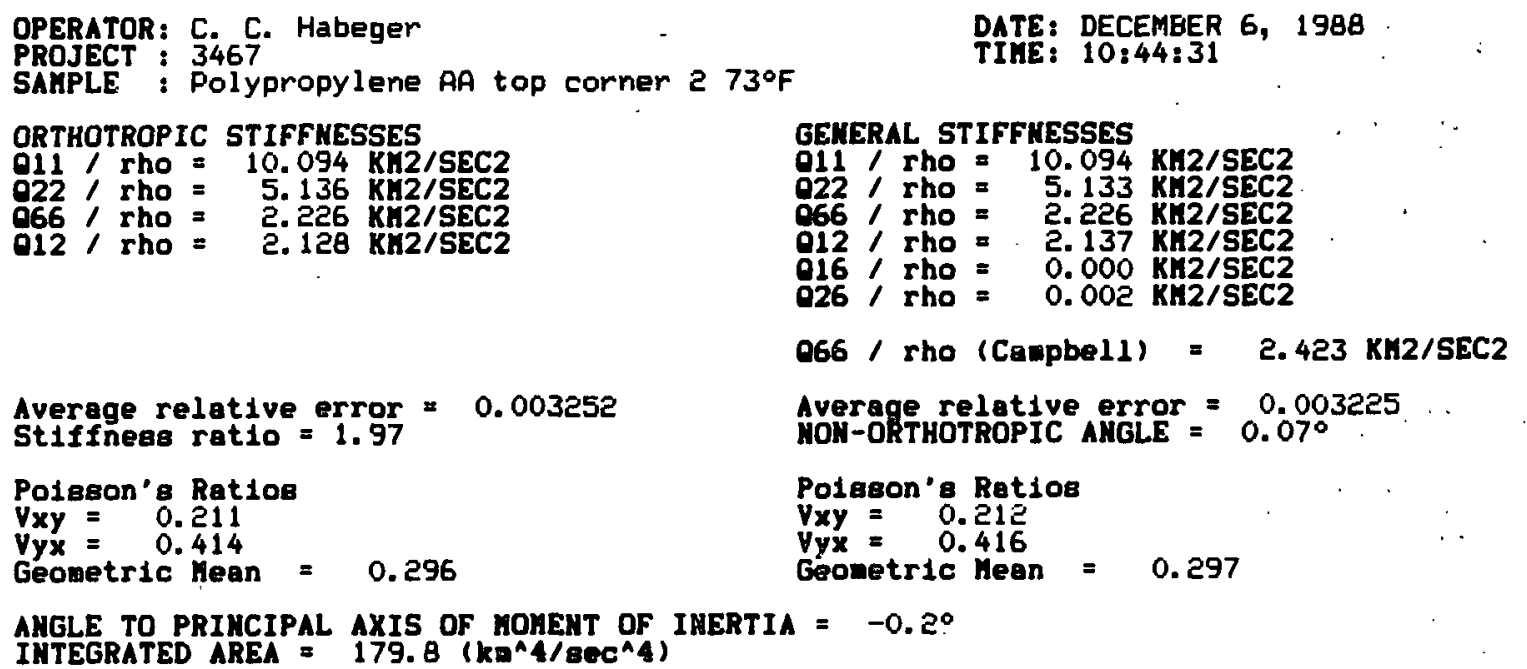

POLAR PLOT OF LOMGITUDIMAL MASS SPECIFIC STIFFHESS

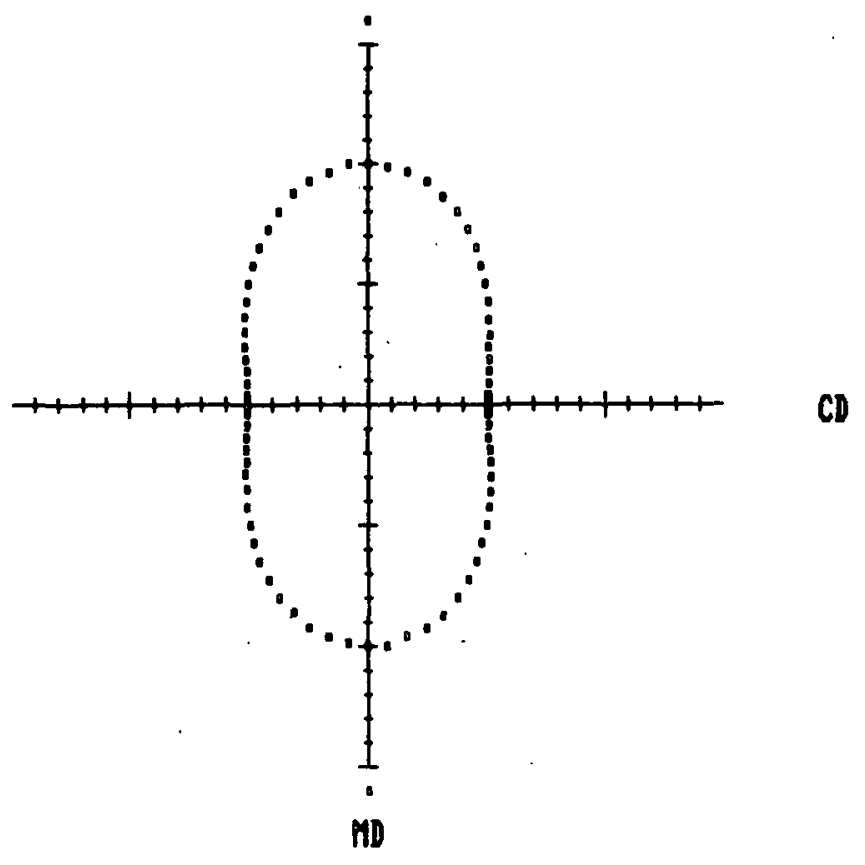

PLOT OF SPBCIFIC STIPFHESS

(Graph Scale $=1 \mathrm{kon} 2 / \mathrm{sec}^{\wedge} 2 / \mathrm{div}$ )

Fig. 4. A computer printout of the elastic stiffnesses of a polyester sheet from a best fit to the plane waves velocity squared polar plot. 
THE IMSTITUTE OF PAPER CHEMISTRY

ROBOTIC IN-PLAHE ULTRASONIC VELOCITIES

OPTIMUM MASS SPECIFIC STIFFNESSES FROM LEAST SOUARED

FIT TO LOMGITUDIKAL PHASE VELOCITY

OPERATOR: C. C. Habeger

PROJECT : 3467

DATE: DECEMBER 6, 1988

SAMPLE : Polyester 121 top corner 273 of

TIHE: $11: 49: 31$

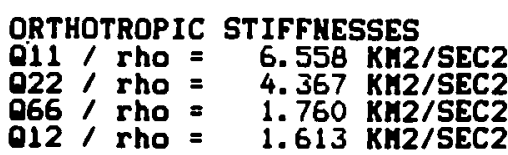

GENERAL STIFFHESSES

Q11 / rho $=6.554 \mathrm{kH2} / \mathrm{SEC} 2$

$022 /$ rho $=4.372 \mathrm{KH2} / \mathrm{SEC} 2$

$066 /$ rho $=1.760 \mathrm{KH} 2 / \mathrm{SEC} 2$

$012 /$ rho $=1.636 \mathrm{kH2} / \mathrm{SEC} 2$

$016 /$ rho $=-0.034 \mathrm{KH2} / \mathrm{SEC} 2$

$026 /$ rho $=0.045 \mathrm{kH} 2 / \mathrm{SEC} 2$

066 / rho (Canpbe11) = $1.830 \mathrm{KH} 2 /$ SEC2

Average relative error $=0.005669$

Average relative error $=0.002047$

Stiffness ratio $=1.50$

0.05669

Polbeon's Rat1or

$\begin{aligned} V_{x y} & =0.246 \\ V_{y x} & =0.369\end{aligned}$

$V y x=0.369$

Geometric Mean =

0.301

Polseon's Ret1os

Poisen $=0.250$
$V y x=0.374$

Vyx = 0.374

0.306

AHGLE TO PRINCIPAL AXIS OF MOMENT OF IMERTIA $=-34.1^{\circ}$

IHTEGRATED AREA $=93.0\left(k^{\wedge} 4 / \mathrm{Bec}^{\wedge} 4\right)$

POLAR PLOT OF LONGITUDIMAL MASS SPECIFIC STIFFMESS

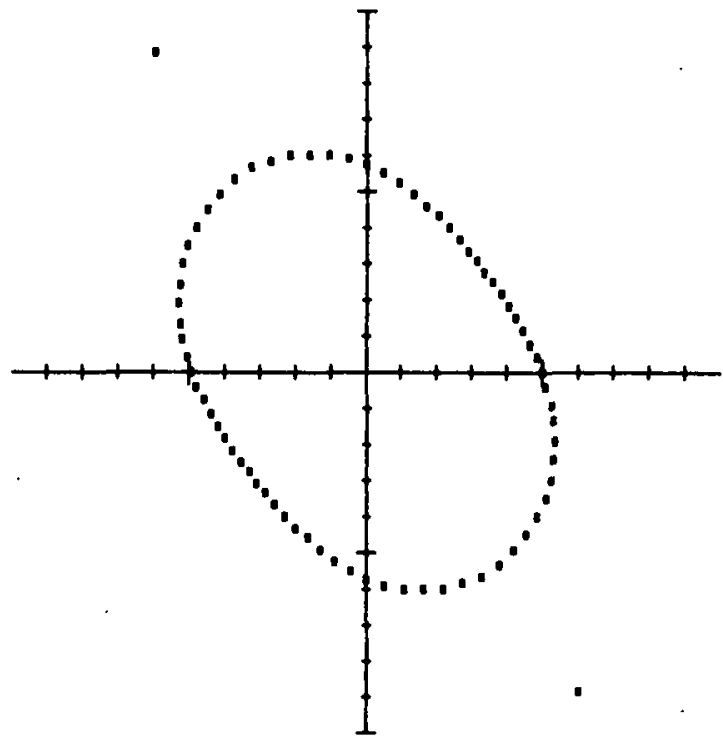

CD

nD

PLOT OF SPECIFIC STIFTHESS

(Graph Scale $=1 \mathrm{~km} 2 / \sec ^{\wedge} 2 / \mathrm{div}$ )

Fig. 5. A computer printout of the measured values of the information propagation velocity squared for the three-ply polyester laminate. 